\section{Understanding and Correlating of Chemical Engineering Thermodynamics I and Process Heat Transfer through Integrated Project}

\author{
Shafirah Samsuri *, Shuhaimi Mahadzir, Wan Nur Aisyah Wan Osman \\ Department of Chemical Engineering, Universiti Teknologi PETRONAS, \\ 32610 Seri Iskandar, Perak, Malaysia \\ *shafirah.samsuri@utp.edu.my
}

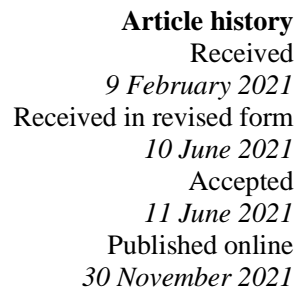

Article history

ebruary 2021

10 June 2021

11 June 2021

O November 2021

\begin{abstract}
The development of engineering education plays a significant role in creating a competency base for engineering students to be excellent in engineering practice as well as other professional skills such as communication, teamwork and leadership. Project-Based Learning via Integrated Project entitled Heat Recovery from Ammonia Synthesis Reactor for Power Generation was introduced as a new learning approach for First Year First Semester Chemical Engineering student to replace the conventional learning approach via lecture. This integrated project is a hybrid of two core Chemical Engineering subjects for First Year students: Chemical Engineering Thermodynamics I and Process Heat Transfer. This integrated project aims to evaluate students' ability to relate two different subjects when learning in the same semester and apply them to the same application. This integrated project is expected to enhance students' learning curve and ensure that the output of this study can be achieved in a consistent effort and timely manner. Assessments in formative (reflection and peer review) and summative (final report) are applied to the students via individual and group. Based on the reflection's analysis, 50\% of the students mentioned that the project is very challenging; meanwhile, only $30 \%$ agreed that they could relate the project with both subjects even though it is complex and challenging. Despite that, $70 \%$ of the students stated that their learning goal is achievable. They were able to view the industrial application, especially the heat exchanger application, through this project. Overall, $90 \%$ agreed that they achieved this integrated project's objectives: to relate two different subjects when learning in the same semester and apply them to the same application. Hence, it is noteworthy to highlight that this integrated project is carefully mapped. The new learning approach via Project-Based Learning brought positive outcome towards the students' learning experiences, skills and understanding.
\end{abstract}

\section{Introduction}

Engineers must have interpersonal, communication, and management skills to be flexible in dealing with the public, exposed to global scenarios, and effectively facing current and future challenges. In Malaysia, the engineering education model is expected to train future engineers to be excellent in engineering practice and great leaders, including strengthening scientific knowledge and professional skills. It is a competency base for engineering students to achieve global recognition and accreditation as capable engineers and leaders (Megat Mohd Noor et al., 2002). Therefore, educators play essential roles in providing effective yet efficient teaching and learning approaches for those students.

Most engineering students could not relate to the courses they learned and could not apply the knowledge in actual applications; hence, they would limit themselves to solve complex engineering problems and problems in the industry. Problems, especially in industry, need to be solved quickly and cost-effectively; thus, project-based learning encourages students to develop practical design thinking and problem-solving skills, especially throughout their undergraduate studies, to be great engineers and leaders future. The traditional learning approaches of using lectures are ineffective (Aziz et al., 2013; Lukman et al., 2013; Mamat \& Mokhtar, 2008); hence the transformation from those conventional learning are needed.

Moon et al. (2007) proposed a better learning approach where the students can participate actively and relate to real-life situations. This is where projectbased learning came to light to replace traditional learning approaches (Azizan et al., 2018). Unlike the conventional teaching method, the lecturers prepare a related problem statement and guide the students (Tatar and Oktay, 2011). According to Nielsen (2003), the first and only university built in 1974 on projectbased learning implementation was Aalborg University, located in Denmark. Project-based learning is a new learning approach introduced to create more engaging learning environments while increasing the students' interest and improving their grades and skills aligned with the new era of the 4th Industry Revolution to create intelligent industries.

In addition, Jumaat et al. (2017) support the implementation of project-based learning to enhance the learning journey of students, especially in terms of constructivism point of view. Theoretically, constructivism is defined as a learning theory where students created their understanding based on their knowledge and experience (Glaser \& Resnick, 2016). In 
the 1900s, Dewey (1916) mentioned that learning should become an active constructive approach instead of a passive absorption method. Furthermore, Biggs (2003) suggested that constructive alignment is the best approach to optimize the learning quality. By definition, 'constructive' is where the student is the one who should construct the learning and actively participate in the learning activities, while 'alignment' is where the teacher needs to align with the learning activities as they need to provide the best environment which could achieve desired learning outcomes (Biggs, 2003). This is in line with the statement made by Tyler (1989) where "Learning takes place through active behaviour of the student, it is what he does that he learns, not what the teacher does".

Hence, project-based learning comes forward as the best approach to reflect the constructivism theory as it required a practice where the student needs to complete the task based on real-world situations. This approach is denoted as the student-centred approach as students are the ones who need to be responsible for exploring critical knowledge and meaningful experience through series of learning activities (Kelly, 2014). According to Helmi et al. (2020), studentcentred approaches allow students to be active throughout their learning journey. This approach seems important to ensure that students have enough knowledge and experience to face real-life situations, especially in this century. The world is currently facing a new pandemic known as Covid-19, which required many transformations in skills, especially for professionals, including engineers. Hence, conventional learning through lectures cannot be comprehended, but more student-centred learning approaches need to be introduced. Moreover, this approach also requires students to find the solution via hands-on investigation that needs to be done in a group (collaborative environment) (Yam \& Peter, 2010). Hence, by introducing this approach, student at the same time able to strengthen their knowledge and improve their professional skills.

In 2009, Reaburn et al. (2009) conducted a study to redesign the undergraduate course by focusing on student interaction and engagement throughout the learning process. Generally, the concept of constructive alignment was applied for the undergraduate course was redesign. From the result, it was found out that the study successfully achieved the objective where student interaction and engagement was improved in terms of learning and assessment tasks. Meanwhile, in 2017, Aziz et al. (2017) introduced a real-world problem for a Chemical Engineering student in the First Year from Universiti Teknologi Malaysia (UTM), where integration of three pillars of sustainable development (Environment, Economic and Social) was used. They claimed that the problem related to industry made the problem more realistic and increased the students' exposure to real-life situations. Similar approach was introduced in this study which involves the concept of project-based learning via an Integrated Project entitled Heat Recovery from Ammonia Synthesis Reactor for Power Generation. From the definition of project-based learning, students are challenged to develop a plan and create a product that addresses the problem. Like this integrated project, in this study, students were required to design a power plant generated from the recovered heat of ammonia synthesis reactor. This approach covers two core Chemical Engineering subjects in First Year curriculum: Chemical Engineering Thermodynamics I and Process Heat Transfer. These subjects are compulsory for Chemical Engineering students to learn. For this project, some research questions were considered in enhancing the students' studies:

- How can the project help the students to learn innovatively?

- How to develop a project that can encourage the students to seek the project's succession?

- How can the project help the students to relate two different courses together?

- What are the students' responses to the project?

\section{Integrated Design Implementation}

Integrated Project in this study is used to maximize the students' knowledge in relating two different subjects when they learn it in the same semester and help the students apply those two different subjects towards the same application. In this study, the integrated project is one hybrid project that combines two core Chemical Engineering subjects: Chemical Engineering Thermodynamics I and Process Heat Transfer in a single project for First Year Chemical Engineering student in their third semester. The implementation of project-based learning in this integrated project is illustrated in Figure 1. All assessment, such as the final report was done in the group, while the reflection and peer review were based on the individual. The reflection and peer review were done to observe the students' feedback to motivate them and make their learning journey more enjoyable.

The project is expected to enhance students' learning curve and make sure that the output of this study can be achieved in a consistent effort and timely manner. The project is run for one semester only and compulsory for the students in that semester. Eleven students were divided into a small team of 3-4 students per group. Universiti Teknologi PETRONAS (UTP) has three intakes per year: January, May, and September. All of these students in this study were from the January intake. This batch has small number of students as they are usually students who took foundation or diploma in other institutions. The May and September student intakes are the ones with the most number of students enrolled as most of them undergo Foundation in Engineering courses in UTP. 
Project-based learning (PBL)

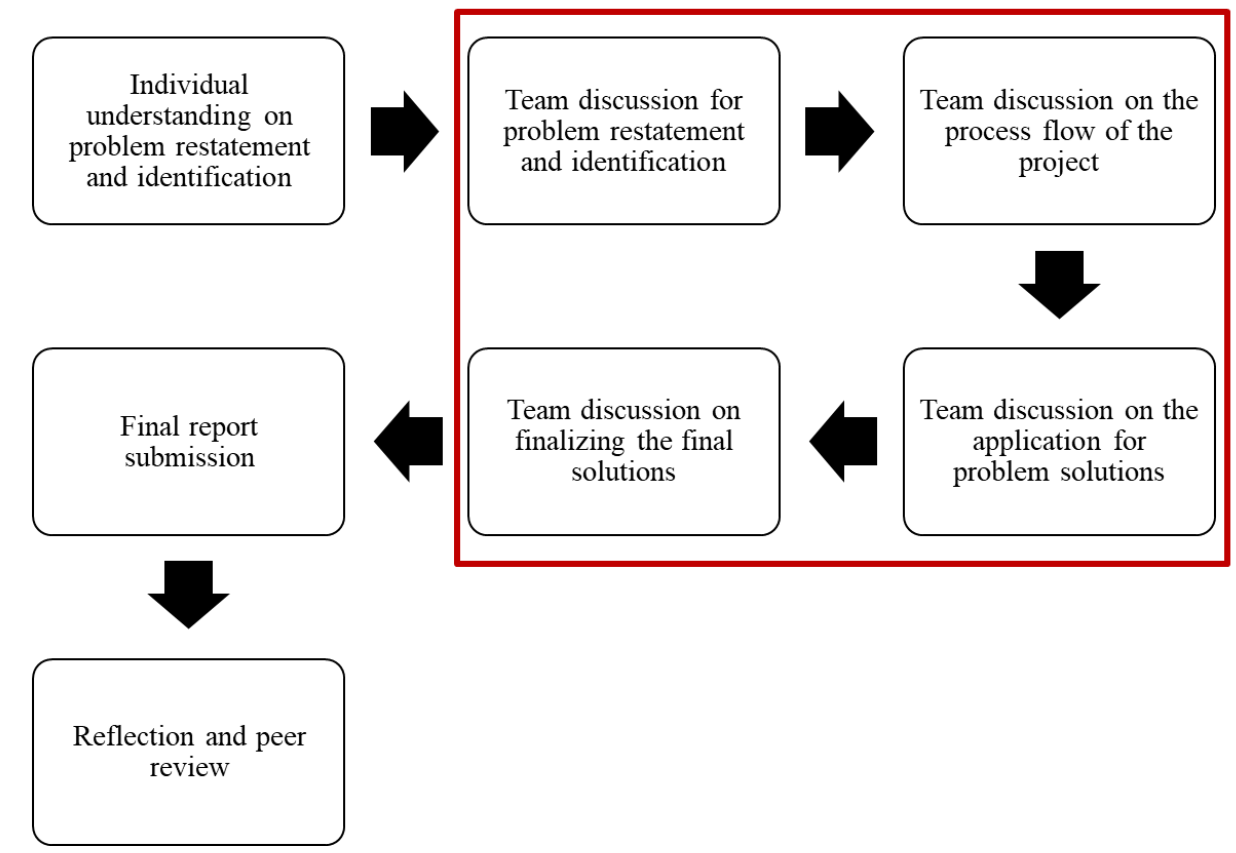

Figure 1. Process Flow for Integrated Project entitled Heat Recovery from Ammonia Synthesis Reactor for Power Generation with the implementation of Project-Based Learning

Assessments in formative (reflection and peer review) and summative (final report) are applied to the students via individual and group. The integrated project is in line with the constructive alignment framework. The appropriate assessments were designed from the course learning outcomes such as project report, peer rating, and reflection. The teaching and learning activities were prepared from these designed assessments, such as lectures, tutorials, an adjunct lecture from industry and additional online consultation session. Table 1 shows the course learning outcome related to the project.

\section{Table 1. Course learning outcome}

\begin{tabular}{|l|l|}
\hline \multicolumn{1}{|c|}{ Course } & \multicolumn{1}{c|}{ Course learning outcome } \\
\hline $\begin{array}{l}\text { Chemical } \\
\text { Engineering } \\
\text { Thermodynamics I }\end{array}$ & $\begin{array}{l}\text { Perform related calculations } \\
\text { and apply them in various } \\
\text { thermodynamics systems. }\end{array}$ \\
\hline $\begin{array}{l}\text { Process Heat } \\
\text { Transfer }\end{array}$ & $\begin{array}{l}\text { Design and evaluate the } \\
\text { performance of heat exchange } \\
\text { devices. }\end{array}$ \\
\hline
\end{tabular}

Through this integrated project, only one problem statement is given on one application in week 4 , and the students need to solve the problem in a team. The purpose is to evaluate the students fairly. An Aspen HYSYS simulation file containing an ammonia reactor was provided to the students. The students are required to use the given reactor effluent stream to execute the project tasks. The students are responsible for gathering information, evaluating the resources, solving the problem, and discussing the solution. The detail on the specific tasks assigned to the students is illustrated in Figure 2. This integrated project helped the student relate and apply two subjects in one application and encouraged them to improve their soft skills such as communication, teamwork, and leadership.

A special online session using Microsoft Teams was conducted to guide the students in completing the project. The lecturers and students previewed the problem statement and discussed the content critically. Students were free to ask questions and were given feedbacks or suggestions by their lecturers. The lecturers facilitated and coached the students along the task throughout the semester. An illustration of the suggested power plant was drawn to guide the students with their proposed design. During the class session, the progress of the project needs to be explained to the lecturers. There were a total of two sessions (2 hours per session) for each subject (Chemical Engineering Thermodynamics I and Process Heat Transfer) per week. All online session were recorded, and the lecturers and students were free to access the recorded videos in Microsoft Stream. From there, the lecturers can again provide feedback and keep track on their progress. 


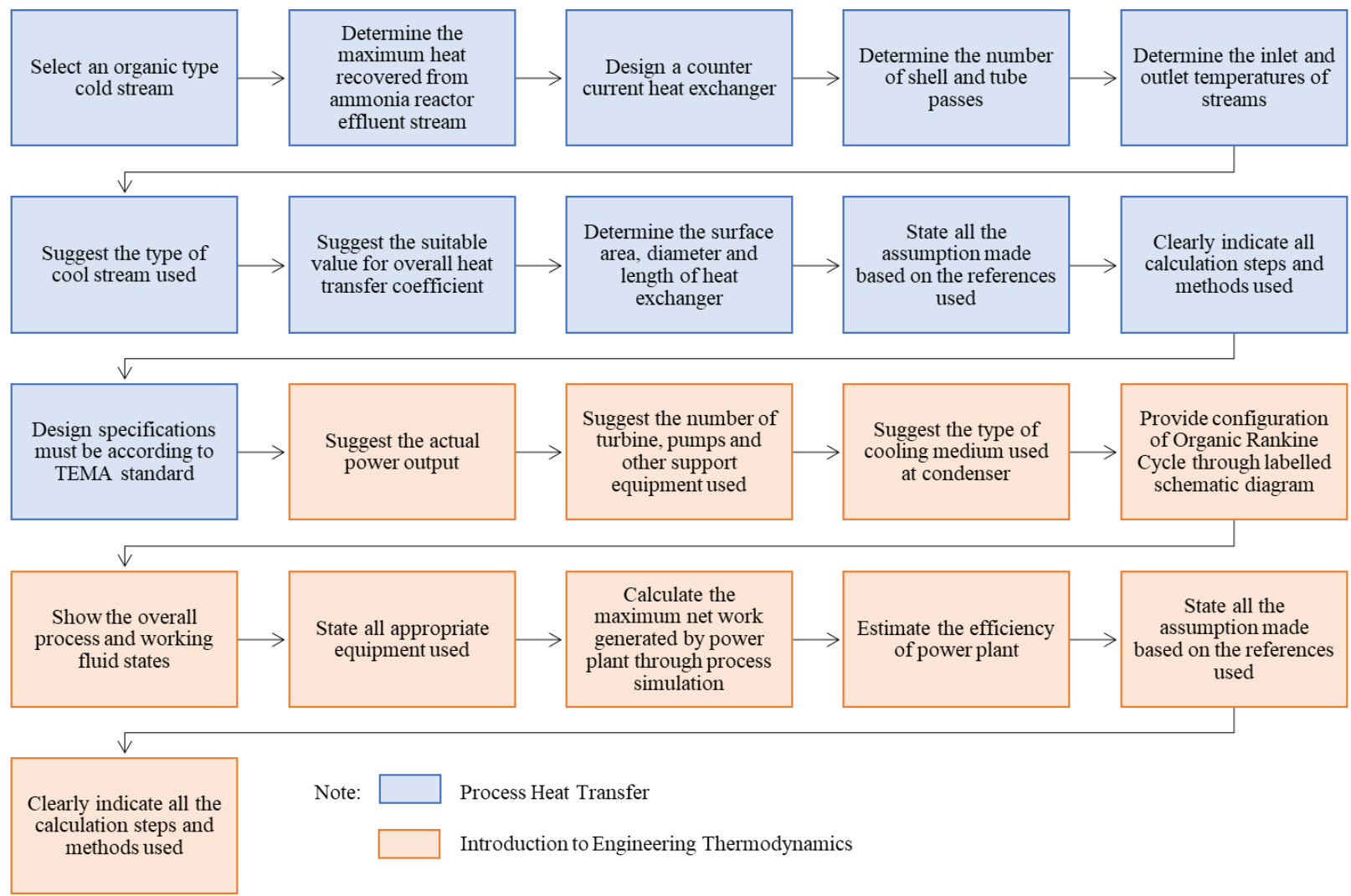
Figure 2. Specific Task for Integrated Project combining Chemical Engineering Thermodynamics I and Process
Heat Transfer subjects

Besides, an adjunct lecture with a principal engineer from Malakoff Power HQ was conducted, as shown in Figure 3. The talk on a gas turbine system was advantageous to the students as the gas turbine system is one of the examples of cycle used in power plant. This sharing session provided the students with clearer view on how a real power plant operates and gave ideas on designing the process as instructed in the integrated project.

At the end of the session, the engineer managed to provide feedback, as follows:

"Good program for the students to be exposed to the industrial application on the knowledge gained from the university. It is also a good platform for me to give back for the good of future generations. Doing this through a virtual platform, travelling can be eliminated, but it is somewhat difficult to gauge the level of the presentation (too advanced, too detailed and not easily understood?) among the students; something that probably the university lecturer can follow through and give feedback or enquiry to me. I would also be grateful for any feedback on my session (contents, explanation, etc.) so that we can further improve in the future session."

At the end of the semester, after submitting the project report, students were required to write and submit peer rating and reflections on their experience with the integrated project. Online medium such as Microsoft Form was used for the students to post their reflections. Microsoft Word softcopy of peer rating was used for students to submit the peer rating. As for the peer rating, each student was required to evaluate their team members. The evaluation form is shown in Figure 4.

Meanwhile, for the reflections, three questions were asked to the students as follows.

1. How did you feel, and what did you think of the project?

2. Did the experience from the project achieve any of your learning goals?

3. From the project, did you realize that two different subjects are related to each other? 


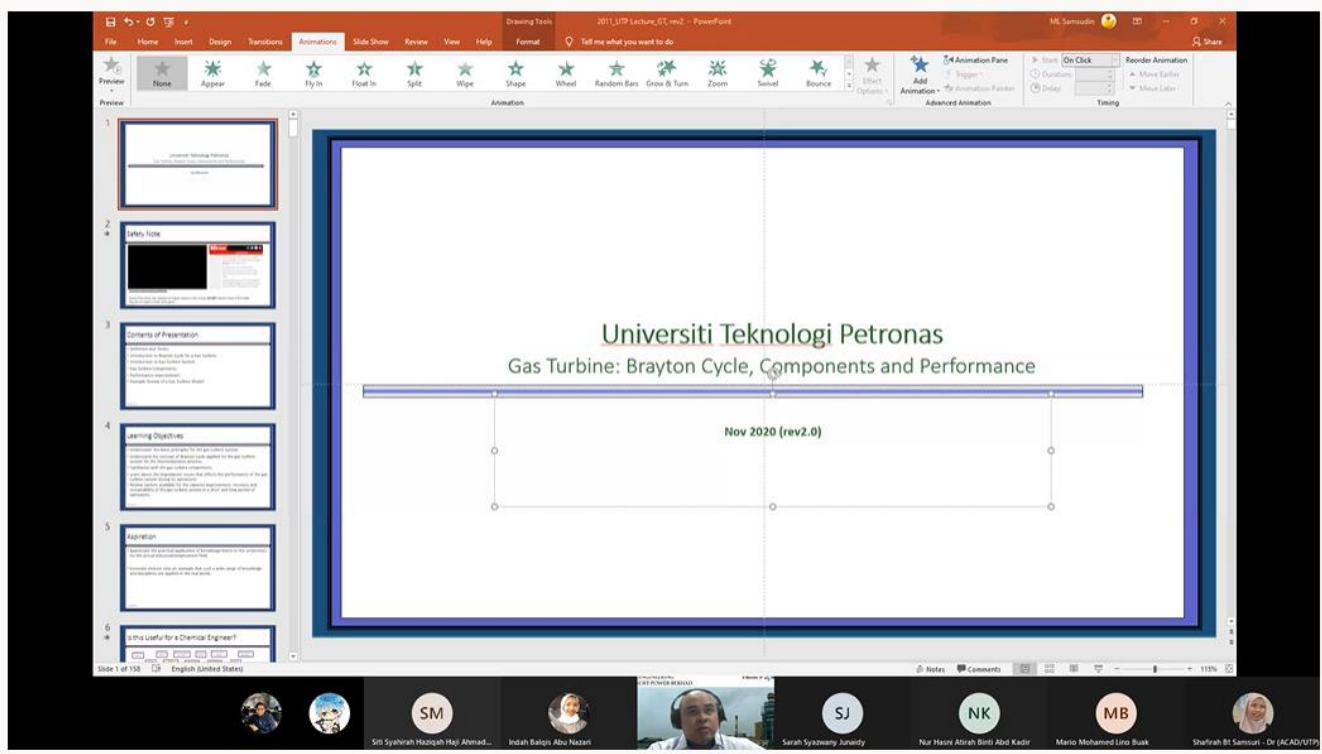

Details

Adjunct Lecture - CEB1072 Chemical Engineering Thermodynamics I

Published on 11/26/2020 by Shafirah Bt Samsuri - $\operatorname{Dr}($ ACAD/UTP) $\quad$ \& Limited 7 () 00

Figure 3. Sharing session from Mr Mohamad Lutfi Samsudin, Malakoff Power HQ

Confidential: To be completed by student and submitted to lecturer individually Name:

Student ID:

\begin{tabular}{|c|c|c|c|c|c|c|c|}
\hline \multirow[t]{2}{*}{ Name of Team Member } & \multirow[t]{2}{*}{ ID } & \multicolumn{5}{|c|}{$\begin{array}{c}\text { Evaluation } \\
\text { Maximum marks } 10 \text { for each criteria }\end{array}$} & \multirow[t]{2}{*}{$\begin{array}{l}\text { Overall evaluation } \\
(\mathrm{a}+\mathrm{b}+\mathrm{c}+\mathrm{d}+\mathrm{e}) / 5\end{array}$} \\
\hline & & (a) & (b) & (c) & (d) & (e) & \\
\hline \multicolumn{8}{|l|}{1.} \\
\hline \multicolumn{8}{|l|}{2.} \\
\hline \multicolumn{8}{|l|}{3.} \\
\hline 4. & & & & & & & \\
\hline
\end{tabular}

Criteria: (a) Attending the group meetings

(b) Teamwork and cooperation

(c) Knowledge input to project

(d) Timely and correct completion of project

(e) Contribution to successful completion of project

Assessment scheme:

\begin{tabular}{|c|c|c|}
\hline Average Score & Factor & Scale \\
\hline $7-10$ & 1.0 & Above expectation \\
\hline $4-6$ & 0.5 & Meet expectation \\
\hline $1-3$ & 0 & Below expectation \\
\hline
\end{tabular}

Signature:

Figure 4. Peer evaluation form 


\section{Discussion}

The learning experience gained by the students can be translated based on the reflection done by ten students (out of 11 students) involved in this integrated project, as shown in Figures 5 (Table 2) and 6 (Table 3).

\section{Summary of Reflection from Lecturers}

The integrated project was done in September 2020 semester. During this time, the teaching and learning were done in online mode due to pandemic COVID-19. Concerning the burden of students doing many projects for many subjects in one semester caused the lecturers to discuss and agreed to combine projects from two subjects into one integrated project. Besides, the correlation between two subjects in solving one project can be seen from this integration.

The lecturers were delighted once the students successfully completed the project with their guidance. This was also the output from multiple discussions between students and their respective lecturers. The sharing session (adjunct lecture) by the principal engineer from Malakoff Power HQ triggered students to be more motivated to complete the project. The cycle that involved and the actual equipment utilized in the plant were shown during the session. As the problem statement of the project was related to the existing plant, the students gained a lot of ideas and could relate with the project they solved. The lecturers were satisfied and motivated to pursue and improve the integrated project for future semester.

\section{Summary of Reflection from Students}

Figure 5 summarises the difficulty of this integrated project, and about $50 \%$ of students mentioned that this integrated project is demanding and challenging. Table 2 showed that five students (out of 10 students) agreed that this integrated project is demanding and challenging. It was found that most of them responded similarly to the first question (refer to methodology section).

- "To be honest, it is a challenging project that requires deep understanding and outside knowledge to complete this project."

- "Not too bad, but the project is at a high level."

Meanwhile, about 30\% agreed that even though this integrated project is complex, they managed to relate the project with both subjects: Chemical Engineering Thermodynamics I and Process Heat Transfer. A total of 3 students (out of 10 students) mentioned that they managed to relate both subjects involved in this integrated project, even though the project was complex. On the other hand, $20 \%$ of them ( 2 out of 10 students) stated that the integrated project is challenging. Still, they can complete the integrated project with the help and guidance from both lecturers.

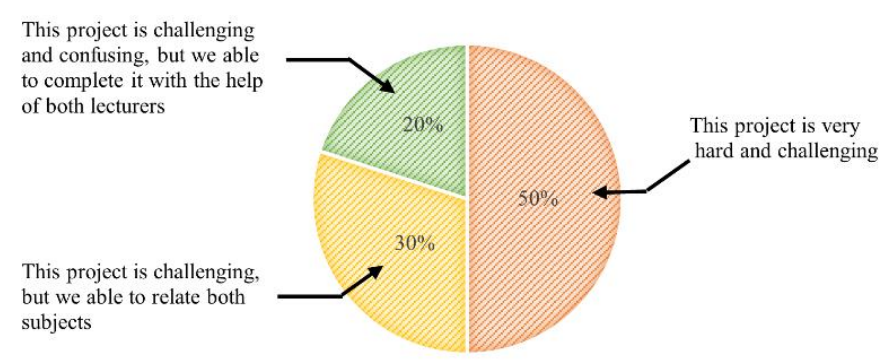

Figure 5. Reflection results on this integrated project level of difficulty (first question)

Table 2. Student's response to the first question

\begin{tabular}{|l|c|}
\hline \multicolumn{1}{|c|}{ Student's respond } & $\begin{array}{c}\text { Number of } \\
\text { students }\end{array}$ \\
\hline $\begin{array}{l}\text { This project is very hard and } \\
\text { challenging }\end{array}$ & 5 \\
\hline $\begin{array}{l}\text { This project is challenging, but we able } \\
\text { to relate both subjects }\end{array}$ & 3 \\
\hline $\begin{array}{l}\text { This project is challenging and } \\
\text { confusing, but we able to complete it } \\
\text { with the help of both lecturers }\end{array}$ & 2 \\
\hline \multicolumn{1}{|c|}{ Total number of student } & 10 \\
\hline
\end{tabular}

On the other hand, for the second question, $70 \%$ of students ( 7 out of 10 students) agreed that this integrated project gave them a clear view of the industrial application, especially on the heat exchanger application. Meanwhile, $20 \%$ of them (2 out of 10 students) stated that the integrated project enhanced their understanding of both subjects and helped them relate both subjects in one application. Only $10 \%$ of them (1 out of 10 students) mentioned that their learning goal is not achievable. However, they still managed to solve the problem. The summarized reflection results on the second question are illustrated in Figure 6 and Table 3.

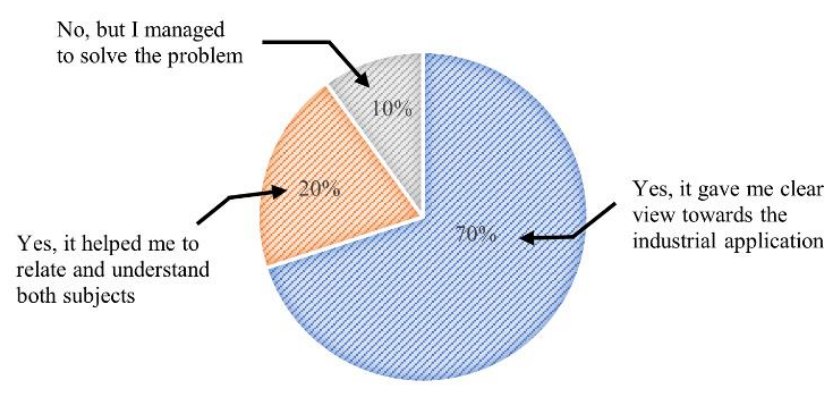

Figure 6. Reflection results on students' learning goal achievable through this integrated project 
Table 3. Student's response to the second question

\begin{tabular}{|l|c|}
\hline \multicolumn{1}{|c|}{ Student's respond } & $\begin{array}{c}\text { Number of } \\
\text { students }\end{array}$ \\
\hline $\begin{array}{l}\text { Agree that this integrated project gave } \\
\text { a clear view of the industrial } \\
\text { application }\end{array}$ & 7 \\
\hline $\begin{array}{l}\text { Agree that this integrated project } \\
\text { helps them to relate and understand } \\
\text { both subjects involved }\end{array}$ & 2 \\
\hline $\begin{array}{l}\text { Disagreed that this integrated project } \\
\text { goal is achievable. However, he/she } \\
\text { managed to solve the problem }\end{array}$ & 1 \\
\hline \multicolumn{1}{|c|}{ Total number of student } & 10 \\
\hline
\end{tabular}

For the third question, based on the reflection analysis, $90 \%$ of the students (9 out of 10 students) achieve this integrated project's objectives which were to relate two different subjects when learning in the same semester and to help them apply those two different subjects on the same application. By comparing the outcome of this integrated project with the conventional learning approach, which is via lecture, the integrated project can improve the students' knowledge and skill. Besides, the integrated project is expected to increase the students' participation in solving the problems. It allows students to work in a group, increasing their motivation, time management, multi-tasking, and leadership skills.

The findings from this study were aligned with the statement made by Azizan et al. (2018), where projectbased learning was introduced to replace the traditional learning approaches (lectures). Moreover, Moon (2007) mentioned a learning approach where students can relate to real-life situations far better than the lectures. Many studies agreed that lectures as learning approaches were ineffective as students could not strengthen their scientific knowledge and professional skills (Aziz et al., 2013; Lukman et al., 2013; Mamat \& Mokhtar, 2008). Both scientific knowledge and professional skills are the essential requirements for students to become engineers who have high capability in engineering practice and can be recognized as great leaders (Megat Mohd Noor et al., 2002).

\section{Conclusions}

In conclusion, the new learning approach with the concept of project-based learning has proven to improve students' thinking and problem-solving skills. Besides, this integrated project increases the students' participation as they need to work in a group to solve the problem. In this study, the Integrated Project introduced is Heat Recovery from Ammonia Synthesis Reactor for Power Generation, covering two core subjects in First Year First Semester of Chemical Engineering studies (Chemical Engineering
Thermodynamics I and Process Heat Transfer). The students' reflection analysis showed that this integrated project achieved the objectives of this study. Most students could relate to two different subjects when learning in the same semester and apply those two different subjects on the same application. Even though $50 \%$ of the students (5 out of 10 students) agreed that the integrated project is complicated and challenging, $70 \%$ of them (7 out of 10 students) mentioned that this integrated project gave them a clear view of the industrial application, especially on heat exchanger application. These results supported the claim that the new learning approach via projectbased learning helps students improve their skills and enhance their understanding of the subjects.

\section{Acknowledgement}

The authors would like to express their appreciation to the Chemical Engineering Department, Universiti Teknologi PETRONAS, for the support. The authors also would like to thank students who had participated in this study.

\section{References}

Aziz, A. A., Yusof, K. M., Sadikin, A. N., Udin, A., Yatim, J. M., \& Hezmi, M. A. (2017). Effective use of Problems in Learning Environments for Attaining Environmental Sustainability Outcomes. 2017 7th World Engineering Education Forum (WEEF), https://doi.org/10.1109/WEEF.2017.8467062

Aziz, A. A., Yusof, K. M., Udin, A., \& Yatim, J. M. (2013). Development of Students' Knowledge-behavioural Changes in Relation to Sustainability through a Case Study. Procedia - Social and Behavioral Sciences, 102, 568-576. https://doi.org/10.1016/j.sbspro.2013.10.773

Azizan, M. T., Mellon, N., Ramli, R. M., \& Yusup, S. (2018). Improving teamwork skills and enhancing deep learning via development of board game using cooperative learning method in Reaction Engineering course. Education for Chemical Engineers, 22, 1-13. https://doi.org/10.1016/j.ece.2017.10.002

Biggs, J. (2003). Aligning teaching and assessing to course objectives. 10.

Dewey, J. (1916). Democracy and Education: An Introduction to the Philosophy of Education. Macmillan.

Glaser, R., \& Resnick, L. B. (2016). Knowing, learning, and instruction: Essays in honor of Robert Glaser. http://search.ebscohost.com/login.aspx?direct=true\&sco pe $=$ site $\& d b=$ nlebk\&db=nlabk\&AN=1920289

Helmi, S. A., Mohd-Yusof, K., \& Zakaria, Z. Y. (2020). Guideline to an Effective Implementation of Student-Centered Learning in Engineering Education: Informal Cooperative Learning (ICL). 7.

Jumaat, N. F., Tasir, Z., Halim, N. D. A., \& Ashari, Z. M. (2017). Project-Based Learning from Constructivism Point of View. Advanced Science Letters, 23(8), 7904-7906. https://doi.org/10.1166/asl.2017.9605

Kelly, N. (2014). Teaching Science in Elementary and Middle School: A Project-Based Approach. Interdisciplinary Journal of Problem-Based Learning, 8(1). https://doi.org/10.7771/1541-5015.1489

Lukman, R., Lozano, R., Vamberger, T., \& Krajnc, M. (2013). Addressing the attitudinal gap towards improving the environment: A case study from a primary school in 
Slovenia. Journal of Cleaner Production, 48, 93-100. https://doi.org/10.1016/j.jclepro.2011.08.005

Mamat, M., \& Mokhtar, F. (2008). Effective instructional design for value dominant education in Malaysian public universities. Social and Management Research Journal, 5, 61. https://doi.org/10.24191/smrj.v5i2.5160

Megat Mohd Noor, M. J., Ali, A., Osman, M., Sapuan, S., Mariun, N., Jaafar, M., Ghazali, A., Omar, H., \& Yusuff, R. (2002). A new engineering education model for Malaysia. International Journal of Engineering Education, 18, 2002.

Moon, J. (2007). Critical Thinking: An Exploration of Theory and Practice. Routledge.

Nielsen, S. H. (2003). The Aalborg Experiment University Industry Interaction: A Means For Stimulating Engineering Excellence In Technology And Learning Systems. 2003 Annual Conference Proceedings, 8.1098.18.1098.12. https://doi.org/10.18260/1-2--11789
Reaburn, P., Muldoon, N., \& Bookallil, C. (2009). Blended spaces, work based learning and constructive alignment: Impacts on student engagement. Proceedings of the 26th Annual Conference of the Australasian Society for Computers in Learning in Tertiary Education, ASCILITE 2009, 820-831. https://research.bond.edu.au/en/publications/blendedspaces-work-based-learning-and-constructivealignment-imp

Tyler, R. W. (1989). Basic principles of curriculum and instruction. Univ. of Chicago Press.

Yam, L. H. S., \& Peter, R. (2010). Implementing a Project-Based Learning Approach in an Introductory Property Course. 19.

Tatar, E. \& Oktay, M. (2011). The effectiveness of problem-based learning on teaching the first law of thermodynamics. Research in Science \& Technological Education, 29, 3. https://doi.org/10.1080/02635143.2011.599318 